\title{
Tingkat Kebisingan dan Perambatan Suara Akibat Bunyi Luar Pada Gereja Masehi Injili Minahasa (GMIM) Kampus Unsrat dan GMIM Bethesda Manado
}

\author{
Sangkertadi ${ }^{1)}$, Ronald Manganguwi ${ }^{1)}$ \\ ${ }^{1)}$ Program Studi Magister Arsitektur, Program Pascasarjana \\ Universitas Sam Ratulangi, Manado, Indonesia \\ email: sangkertadi@unsrat.ac.id
}

\begin{abstract}
ABSTRAK
Penelitian ini bertujuan untuk mengetahui kontribusi dinding dan arsitektur ruang serta jarak gedung ke jalan terhadap reduksi bising dari luar kedalam bangunan, dan distribusi bunyi yang terjadi. Studi kasus pada 2 gereja yaitu gereja GMIM Kampus Unsrat dan gereja GMIM Bethesda Ranotana di Kota Manado. Sebuah sumber bunyi di letakkan di luar ruang dekat pagar pada jarak $12 \mathrm{~m}$ terhadap gedung, dengan kuat bunyi konstan namun bervariasi antara 60 sampai dengan $100 \mathrm{~dB}$ dengan tahapan setiap $10 \mathrm{~dB}$. Kuat bunyi dihitung dan diukur pada setiap jarak $2 \mathrm{~m}$ diruang luar dan dalam Gereja. Pengukuran menggunakan alat sound level meter. Perhitungan menggunakan teori akustik ruang dan software I_Simpa. Hasilnya menunjukkan bahwa konfigurasi arsitektur selubung dan ruang bangunan kedua gereja tersebut dalam keadaan kosong hanya mampu mereduksi bising sebesar 2.2 dan $3.7 \mathrm{~dB}$, dengan jendela terbuka. Dengan sumber suara $100 \mathrm{~dB}$ di ruang luar, hasil pengukuran di ruang dalam pada kedua gereja mencapai $69.3 \mathrm{~dB}(\mathrm{~A})$ dan $56.4 \mathrm{~dB}(\mathrm{~A})$. Rentang bunyi tersebut masih tergolong bising dan belum memenuhi syarat kenyamanan bunyi untuk jenis bangunan ibadah menurut SNI. Visualisasi distribusi bunyi dengan menggunakan software I_Simpa, menunjukkan peran bukaan pintu dan jendela yang menyebabkan kebocoran bunyi kedalam ruangan.
\end{abstract}

Kata kunci: Akustika; bising; dinding; gereja

\section{Noise Level and Sound Propagation Due to Outside Sound at GMIM Church Unsrat Campus and GMIM Bethesda Manado}

\begin{abstract}
This research aims to determine the contribution of walls and architectural interior, and the distance of the building to the road to the reduction of noise from outside into the building as well as the distribution of sound that occurs. Case studies on 2 churches: the GMIM Church of Unsrat Campus and the GMIM Bethesda Ranotana Church, both in Manado City. A sound source was placed outside the room near the fence at $12 \mathrm{~m}$ from the building. The sound source was constant but varied from 60 to $100 \mathrm{~dB}$ with steps every $10 \mathrm{~dB}$. Sound reception was calculated and measured every 2 $\mathrm{m}$ distance at outside and inside. Measurements were carried out using sound level meter. Calculations by acoustic theory and I_Simpa software. The results show that the churches when room is empty, had only able to reduce the noise by 2.2 and $3.7 \mathrm{~dB}$, with opened windows. When a $100 \mathrm{~dB}$ sound source was applied, the measurement results in the indoor of the two buildings reached $69.3 \mathrm{~dB}(\mathrm{~A})$ and $56.4 \mathrm{~dB}(\mathrm{~A})$. Graphical visualizations of sound distribution by using I_Simpa software, showed the role of door and opened window that cause sound leakage into the room.
\end{abstract}

Keywords: Acoustic; church; noise; wall

(Article History: Received 20-08-2021; Accepted 27-09-2021; Published 28-09-2021)

\section{PENDAHULUAN}

Masalah kebisingan tak dapat dihindari, apabila letak bangunan gereja terletak dipinggir jalan dengan volume lalu lintas yang ramai. Paparan bising secara konstan sangat terasa bagi manusia didalamnya akibat kebisingan lalu lintas jalan raya (Mavrin et al., 2018). Kebisingan juga termasuk kategori polusi lingkungan yang membahayakan bagi Kesehatan dan sudah sering terjadi (Drew et al., 2017; Septiana \& Widowati, 2017). Bangunan yang dirancang dengan konsep 
penghawaan alami, senantiasa menerapkan bukaan lebar untuk ventilasi. Hal ini berdampak pada adanya transmisi bunyi bising yang masuk kedalam ruangan melalui lubang jendela dan pintu terbuka. Ini menjadi masalah baru yang perlu dikaji, untuk mencari solusi desain dalam rangka mengurangi bunyi bising didalam ruang. Namun terlebih dahulu perlu diketahui berapa nilai bunyi bising yang berhasil menembus bukaan jendela. Bukaan lebar memang beresiko menerima kebisingan lingkungan luar dan menganggu komunikasi di dalam ruang (Subagio, 2017).

Dalam penelitian ini dilakukan kajian akustika mengenai bunyi bising yang masuk pada ruangan bangunan ibadah, yakni pada kasus gereja GMIM Kampus UNSRAT dan gereja GMIM Bethesda Ranotana, keduanya di Kota Manado. Kedua gereja ini dipilih karena terletak di dekat jalan yang berpotensi menimbulkan bunyi bising. Selain itu jarak bangunan terhadap pagar, tergolong relatif tidak dekat yakni lebih dari $10 \mathrm{~m}$, yang dianggap berpotensi mereduksi bunyi bising cukup baik. Selain itu, kedua gereja tersebut juga dirancang dengan konsep penghawaan alami, dimana terdapat bukaan lebar untuk ventilasi, yang beresiko meneruskan bunyi bising dari luar. Dinding terbuat dari pasangan batu bata diplester semen dan dicat putih. Pada halaman terdapat beberapa pohon, rumput, dan semak bunga, namun tidak tergolong padat. Bangunan ibadah seperti gereja ini perlu dilindungi terhadap resiko bunyi bising, karena bising akan menganggu kekhusukan umat dalam melaksanakan proses beribadah. Bangunan gedung ibadah gereja, di ruang dalamnya harus memenuhi standar maksimal kebisingan sebesar $35 \mathrm{~dB}$ untuk yang berkapasitas sd 250 orang (SNI 03-63862000). Kedua kasus dalam penelitian ini adalah gereja dengan kapasitas sekitar 200 orang. Namun sebaliknya ternyata ada yang melakukan studi tentang tingkat suara dari dalam gereja yang justru bisa berdampak menimbulkan polusi suara terhadap lingkungan sekitarnya (Bojongo, 2020; Gemade \& Inja, 2020; Christan \& Eberechi, 2019), dan yang berdampak kebisingan pada jemaat didalamnya (Ibekwe, 2018). Konfigurasi jendela yang terbuka masih dapat mereduksi bunyi bising meskipun tidak besar, namun dengan bukaan yang tidak terbuka sepenuhnya masih diharapkan mendapatkan reduksi bising yang cukup baik. Mediastika
(Mediastika et al., 2018) melakukan percobaan laboratorium untuk mengetahui peluang jendela terbuka terhadap reduksi bising. Hasil penelitiannya menunjukkan bahwa jendela yang dibuka miring 10 derajat, masih mampu mereduksi $5 \mathrm{~dB}$. Sedangkan apabila miringnya hanya 5 derajat, mampu mereduksi sebesar $7 \mathrm{~dB}$. Kajian Du et al. (2019) tentang reduksi bising karena ventilasi kaca dengan permeabilitas sekitar 20\%, hasilnya menunjukkan adanya peluang reduksi bising sekitar 8 sd $12 \mathrm{~dB}$ yang tergantung pada oktaf yang diterapkan. Sedangkan hasil penelitian dari Barbara Locher, dkk (Locher et al., 2018) tentang transmission loss jendela terbuka pada apartemen, menunjukkan hasil bahwa pengurangan kebisingan dapat terjadi sebesar $10 \mathrm{~dB}$, dimana ruang dalamnya tergolong bukan ruang yang memiliki serapan bunyi yang cukup baik.

Dalam kasus ini, bukaan jendela pada gereja GMIM Kampus Unsrat dan GMIM Bethesda Ranotana, luasannya sekitar 30\% terhadap dinding selubung. Dengan luasan bukaan tersebut tentu memiliki pengaruh reduksi bising yang tidak signifikan apabila membandingkan dengan studi yang pernah dilakukan oleh peneliti lain. Namun demikian melalui penelitian ini ingin diketahui besarnya reduksi bising yang terjadi pada kasus kedua Gereja tersebut, baik karena faktor jarak sumber bunyi terhadap bangunan maupun terhadap pengaruh bukaan jendela. Dengan demikian, akan dapat disimpulkan apakah ruang dalam Gereja sudah memenuhi syarat standar maksimal kebisingan atau tidak. Selain itu juga hendak diketahui pola garis kontur rambatan bunyi dari luar ke dalam.

\section{METODE PENELITIAN}

Penelitian ini berjenis kuantitatif, dengan menerapkan pengukuran lapangan, perhitungan dengan spread sheet, dan perhitungan menggukan paket program aplikasi (software).

\section{Pengukuran}

Dalam proses pengukuran kuat bunyi, di gunakan alat sound level meter untuk mengukur besarnya kuat bunyi dengan satuan $d B(A)$. Sebagai sumber bunyi dioperasikan suara sebuah kendaraan bermotor roda dua secara konstan, dengan besarnya kuat bunyi sebesar 60, 70, 80, 90, $100 \mathrm{~dB}$. Jadi terdapat 5 
jenis kuat suara berbeda dari satu sumber bunyi. Angka $100 \mathrm{~dB}$ diambil berdasarkan pertimbangan standar bunyi klakson, dimana berdasarkan PP No. 55 tahun 2012 paling rendah $83 \mathrm{~dB}(\mathrm{~A})$ dan paling tinggi $118 \mathrm{~dB}(\mathrm{~A})$. Jarak pengukuran dilakukan setiap jarak $2 \mathrm{~m}$ dari sumber bunyi ke dalam ruangan. Pada setiap titik dilakukan pengukuran sebanyak 3 kali. Ketinggian alat sound level meter pada posisi $1.5 \mathrm{~m}$ dari lantai. Metode pengukuran juga mengacu pada lampiran II keputusan menteri lingkungan hidup nomor: KEP48/MENLH/11/1996.

\section{Perhitungan}

Perhitungan reduksi kebisingan karena faktor jarak (antara sumber bunyi dan penerima) yang umumnya di pakai untuk kasus ruang luar, mengacu pada rumus umum rambatan bunyi yang didasarkan pada pola sebaran bunyi yang bersifat membola, dengan persamaan umum teori akustika tentang distribusi bunyi dan NR sebagai berikut (Patel, 2020)

$I_{1}=\frac{P}{4 \pi\left(r_{1}\right)^{2}} ; \quad I_{2}=\frac{P}{4 \pi\left(r_{2}\right)^{2}} ; I_{n}=\frac{P}{4 \pi\left(r_{n}\right)^{2}}, ;$ dan $T I=10 \log \frac{I}{I_{o}} ;$

$$
\Delta T I=T I_{2}-T I_{1}=10 \log \frac{I_{2}}{I_{o}}-10 \log \frac{I_{1}}{I_{o}}
$$

dimana $I$ adalah kuat intensitas bunyi, dan $r$ adalah jarak terhadap sumber bunyi, $P$ adalah daya bunyi dan $T I$ adalah taraf intensitas bunyi. Sedangkan reduksi kebisingan didalam bangunan karena faktor serapan bunyi ruangan penerima dan sumber bunyi di ruangan lain, dapat di estimasi dari pendekatan melalui rumus umum Noise Reduction (NR) (Patel, 2020) :

$$
\begin{aligned}
& N R=T I_{1}-T I_{2} \\
& N R=S R I-10 \log \frac{A_{S}}{\sum A_{i(2)} \alpha_{i(2)}}
\end{aligned}
$$

dimana $T I_{1}$ adalah taraf intensitas bunyi di luar, $T I_{2}$ adalah Taraf Intensitas di ruang dalam; SRI adalah Sound Reduction Index dari dinding sekat, dan $\alpha$ adalah koefisien serapan bunyi dari permukaan dinding ruang penerima bunyi, $A_{i}$ adalah luas dinding yang berkaitan di ruang penerima. $A_{s}$ adalah luas sekat. Jadi hasil pengukuran $T I_{I}$ dan $T I_{n}$ selanjutnya dijadikan input pada proses perhitungan, untuk memperoleh besarnya $N R$ dan $S R I$. Dalam penelitian ini nilai awal $S R I$ ditetapkan sebesar $8 \mathrm{~dB}$ yang nengacu pada hasil penelitian oleh Du et al. (Du et al., 2019).
Dalam perhitungan ini ruangan dianggap terisi penuh 200 orang.

\section{Simulasi dengan Program I_Simpa}

I_Simpa adalah paket program untuk perhitungan dan visualisasi distribusi rambatan bunyi. Dalam penelitian ini, digunakan untuk pembandingan terhadap hasil perhitungan (manual) dan terhadap hasil ukur, serta untuk memvisualisasikan pola garis kontur penyebaran bunyi dari luar ke dalam bangunan. Pada proses perhitungan yang menggunakan software ini, ruangan dianggap kosong.

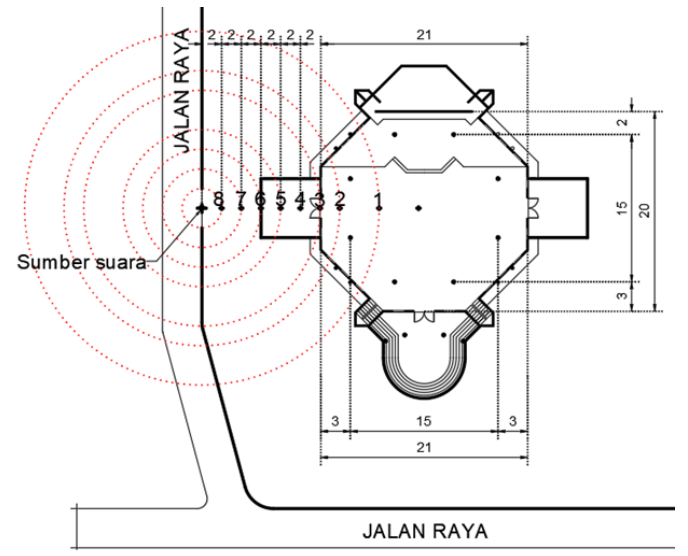

Gambar 1. Denah Gereja GMIM Kampus, dan posisi titik ukur

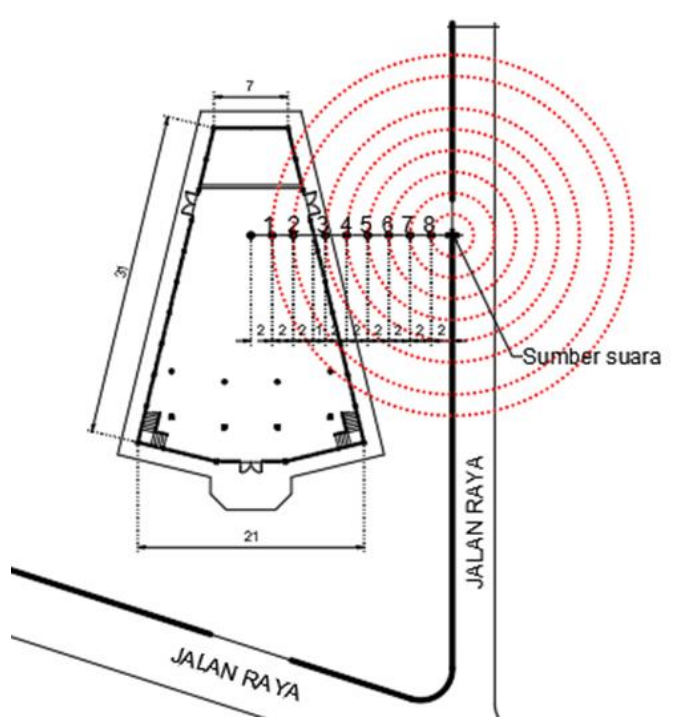

Gambar 2. Denah Gereja GMIM Bethesda dan posisi titik ukur

\section{HASIL DAN PEMBAHASAN}

Hasil pengukuran menunjukkan adanya penurunan kuat bunyi yang cukup signifikan dari sumber bunyi di ruang luar sampai ke dalam bangunan, pada dua kasus bangunan 
Gereja. Pada pengukuran di gereja GMIM Kampus, hasilnya ditampilkan pada Gambar 3. Pada gambar tersebut juga ditunjukkan adanya fluktuasi kuat bunyi pada jarak tertentu, khususnya pada kasus sumber bunyi 70 sd $90 \mathrm{~dB}$. Hal ini dapat terjadi karena adanya intervensi bunyi latar selain sumber bunyi yang direncanakan. Bunyi latar tersebut dapat bersifat memperkuat atau memperlemah kuat bunyi, sebagaimana juga hasil kajian dari Mama dkk (Mama et al 2018). Dengan sumber bunyi $100 \mathrm{~dB}$, ternyata dapat terdengar sampai sebesar $67.1 \mathrm{~dB}$, atau terjadi $N R$ (Noise Reduction) sebesar $32.9 \mathrm{~dB}$. Namun dengan sumber bunyi $70 \mathrm{~dB}$, ternyata $N R$ yang tercapai hanya sebesar $8.6 \mathrm{~dB}$, yang merupakan selisih dari $70 \mathrm{~dB}$ dengan $61.4 \mathrm{~dB}$. Sebagai perbandingan, penelitian sejenis dari Mediastika (2018), menghasilkan $N R$ pada kisaran 5 ssampai dengan $10 \mathrm{~dB}$. Adapun hasil kajian dari $\mathrm{Du}$ (Du et al., 2019) juga menunjukkan hasil NR dapat berkisar antara 8 sd 12 dB. Selain itu bunyi yang terdengar di ruang dalam ternyata masih tidak memenuhi standar kebisingan menurut SNI 03-63862000, yang semestinya maksimum sebesar 35 dB. Demikian pula terdapat perbedaan nilai $N R$ untuk kasus dengan sumber bunyi lainnya yaitu yang $80 \mathrm{~dB}$ dan $90 \mathrm{~dB}$. Hal yang sama juga terjadi pada pengukuran di Gereja GMIM Bethesda Ranotana (Gambar 4), dimana terdapat pula fluktuasi rambatan bunyi. Sedangkan kuat bunyi didalam ruang, ternyata juga tidak memenuhi standar kebising an ruang ibadah Gereja. Kuat bunyi yang didengar masih jauh melampaui angka minimal.

Pada kasus sumber bunyi $100 \mathrm{~dB}$, dibuat perbandingan cara perhitungan manual, menggunakan program I_Simpa, dan hasil pengukuran. Selain itu juga di buat perhitungan seolah olah tidak ada dinding, dimana hal ini untuk mengetahui perbedaan perhitungan besar TI atau kuat bunyi di dalam ruang dan TI atau kuat bunyi yang tanpa dinding. Perbedaan tersebut adalah sama dengan $N R$, sebagaimana secara implisit tertuang pada Tabel 1 dan 2. Pada Gambar 5 dan 6, juga ditunjukkan pola rambatan penurunan kuat bunyi yang terjadi diruang luar dan ruang dalam.

Sumber bunyi $100 \mathrm{~dB}$ dipilih sebagai bahasan khusus karena dianggap mewakili bunyi klakson, yang mendekati dari kajian Supriatna (Supriatna et al, 2020), bahwa bunyi klakson mobil pada umumnya antara $90 \mathrm{sd}$
102 dB. Hasil perbedaan TI tersebut menunjukkan berapa besarnya $N R$ karena kontribusi arsitektur dinding dan akustik ruang, atau menunjukkan peluang besarnya akumulasi SRI dan faktor serapan bunyi dari ruang.

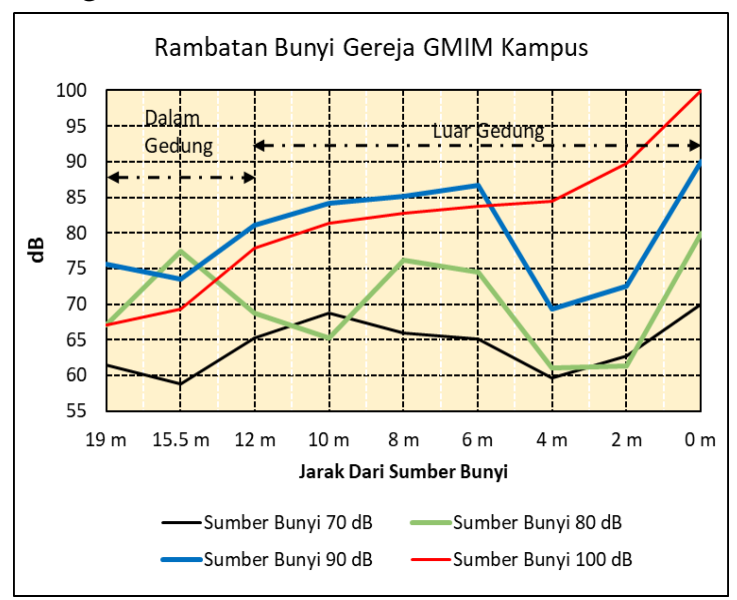

Gambar 3. Hasil pengukuran pada Gereja GMIM Kampus

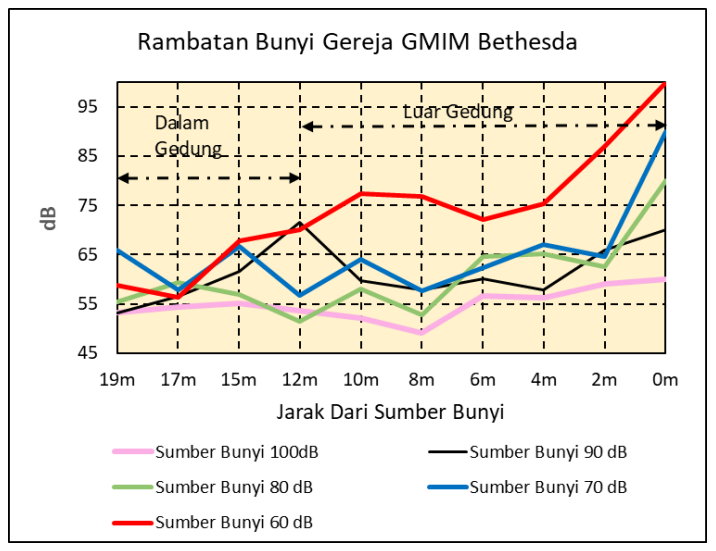

Gambar 4. Hasil pengukuran pada Gereja GMIM Bethesda

Besarnya peluang reduksi bising tersebut disajikan pada Tabel 3. Pada Tabel tersebut, nampak bahwa pada Gereja GMIM Kampus, ternyata reduksi bising secara teoretis dengan perhitungan $N R$ berkisar antara $8.7 \mathrm{sd} 12.7 \mathrm{~dB}$ dalam keadaan ruangan terisi 200 orang. Sedangkan dari hasil simulasi software hanya berikisar $2 \mathrm{sd} 2.2 \mathrm{~dB}$ dalam keadaan ruangan kosong, sementara itu dari hasil pengukuran bisa mencapai $N R$ sebesar $7.5 \mathrm{~dB}$. Demikian pula pada kasus Gereja GMIM Bethesda, dimana secara teoretis nilai $N R$ sebesar sekitar $5.9 \mathrm{sd} 6.4 \mathrm{~dB}$ apabila terisi penuh orang pemakai ruangan. Sedangkan apabila kosong, hanya mampu tereduksi sekitar 2.3 sd $3.4 \mathrm{~dB}$ berdasarkan simulasi menggunakan software I_Simpa, sedangkan menurut hasil pengukuran, $N R$ berpeluang sampai sebesar 16.2 dB dibandingkan apabila 
tidak ada selubung, dalam keadaan tidak ada pengunjung. Sebagai pembanding hasil pengukuran pada Gereja Puh Sarang yang bukaanya seluas 50\% terhadap selubung, hanya mampu mereduksi bising sebesar sekitar $11 \mathrm{~dB}$ pada frekuensi $500 \mathrm{sd} 1000 \mathrm{~Hz}$ (Poetiray, et al., 2015).

Tabel 1. Perbandingan Hasil Perhitungan dan Pengukuran Kuat Bunyi (dB), pada Gereja GMIM Kampus

\begin{tabular}{|c|c|c|c|c|c|c|c|c|c|}
\hline \multirow{3}{*}{$\begin{array}{c}\text { Model } \\
\text { Perhuitungan/ } \\
\text { Pengukuran } \\
\end{array}$} & \multicolumn{9}{|c|}{ Titik Penerima/ Jarak terhadap sumber bunyi } \\
\hline & 1 & 2 & 3 & 4 & 5 & 6 & 7 & 8 & 9 \\
\hline & $19 \mathrm{~m}$ & $15.5 \mathrm{~m}$ & $12 \mathrm{~m}$ & $10 \mathrm{~m}$ & $8 \mathrm{~m}$ & $6 \mathrm{~m}$ & 4m & $2 \mathrm{~m}$ & $0 \mathrm{~m}$ \\
\hline $\begin{array}{l}\text { Teori rambat } \\
\text { bunyi (Asumsi } \\
\text { Tanpa Selubung } \\
\text { Bangunan) }\end{array}$ & 75 & 76.3 & 79 & 80 & 82 & 85 & 88 & 94 & 100 \\
\hline $\begin{array}{l}\text { Perhitungan } \\
\text { Teori NR }\end{array}$ & 65.9 & 63.6 & 79 & 80 & 82 & 85 & 88 & 94 & 100 \\
\hline $\begin{array}{l}\text { Simulasi } \\
\text { Software I } \\
\text { Simpa dg } \\
\text { Menerapkan } \\
\text { Selubung } \\
\text { Bangunan }\end{array}$ & 72 & 74.3 & 79 & 80 & 82 & 84 & 88 & 94 & 100 \\
\hline $\begin{array}{l}\text { Hasil } \\
\text { pengukuran }\end{array}$ & 67 & 69.3 & 78 & 81 & 83 & 84 & 85 & 90 & 100 \\
\hline
\end{tabular}

Tabel 2. Perbandingan Hasil Perhitungan dan Pengukuran Kuat Bunyi (dB), pada Gereja GMIM Bethesda

\begin{tabular}{|c|c|c|c|c|c|c|c|c|c|c|}
\hline \multirow{3}{*}{\begin{tabular}{|c|} 
Model \\
Perhuitungan/ \\
Pengukuran \\
\end{tabular}} & \multicolumn{10}{|c|}{ Titik Penerima/ Jarak terhadap sumber bunyi } \\
\hline & 1 & 2 & 3 & 4 & 5 & 6 & 7 & 8 & 9 & 10 \\
\hline & $19 \mathrm{~m}$ & $17 \mathrm{~m}$ & $15 \mathrm{~m}$ & $12 \mathrm{~m}$ & $10 \mathrm{~m}$ & $8 \mathrm{~m}$ & $6 \mathrm{~m}$ & $4 \mathrm{~m}$ & $2 \mathrm{~m}$ & $\mathbf{0 m}$ \\
\hline $\begin{array}{l}\text { Teori rambat } \\
\text { bunyi (Asumsi } \\
\text { Tanpa Selubung } \\
\text { Bangunan) }\end{array}$ & 75 & 76.1 & 77 & 79 & 80 & 82 & 85 & 88 & 94 & 100 \\
\hline $\begin{array}{l}\text { Perhitunga } \\
\text { Teori NR }\end{array}$ & 69 & 69.9 & 70.8 & 78.6 & 80.1 & 82.1 & 84.6 & 88.1 & 94.1 & 100 \\
\hline \begin{tabular}{|l} 
Simulasi \\
Software I \\
Simpa dg \\
Menerapkan \\
Selubung \\
Bangunan \\
\end{tabular} & 71.6 & 74.6 & 74.9 & 78 & 80 & 82 & 85 & 88 & 94 & 100 \\
\hline $\begin{array}{l}\text { Hasil } \\
\text { pengukuran }\end{array}$ & 59 & 56.4 & 68 & 70 & 77 & 77 & 72 & 75 & 87 & 100 \\
\hline
\end{tabular}

Selanjutnya dengan menggunakan software I_Simpa, dapat diketahui pola distribusi bunyi mulai dari sumber bunyi sampai pada titik pendengaran di ruang dalam (Gambar 7 dan 8). Nampak pada visualisasi distribusi suara, rambatan tetap bersifat sferis, atau membola, dan Nampak juga adanya peran dinding sebagai penghalang rambatan. Setelah bunyi masuk kedalam ruangan, maka intensitas bunyi sudah berkurang, dimana pola rambatannya hanya dipengaruhi oleh lubang pintu atau jendela pada dinding bangunan.

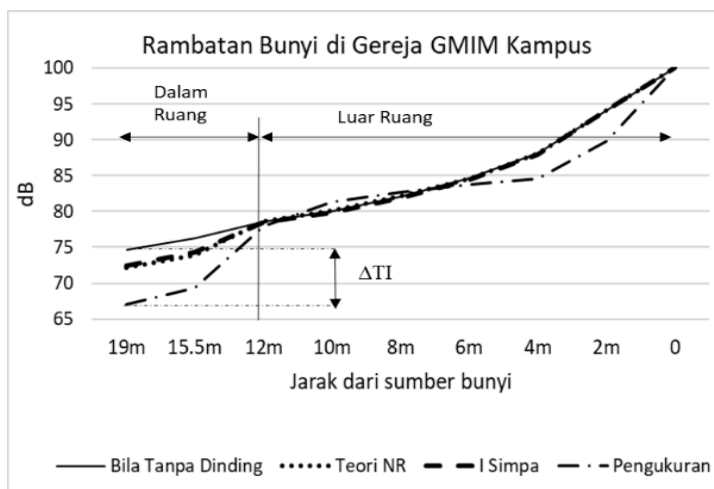

Gambar 5. Rambatan bunyi di Gereja GMIM Kampus dengan sumber bunyi 100dB

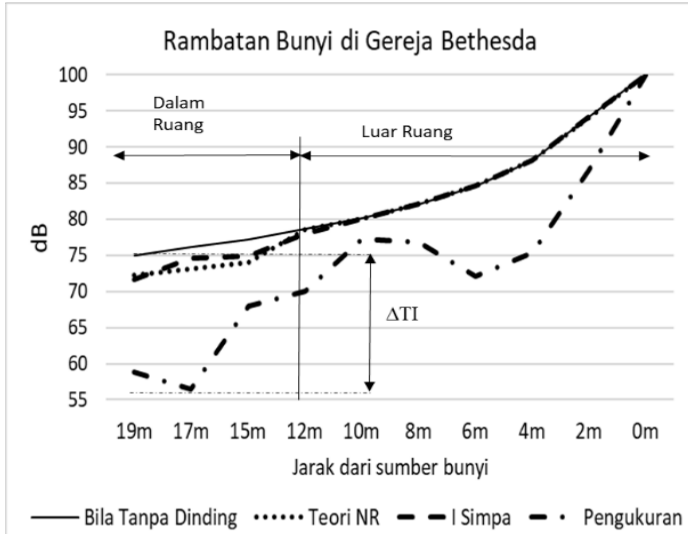

Gambar 6. Rambatan bunyi di Gereja GMIM Kampus dengan sumber bunyi $100 \mathrm{~dB}$
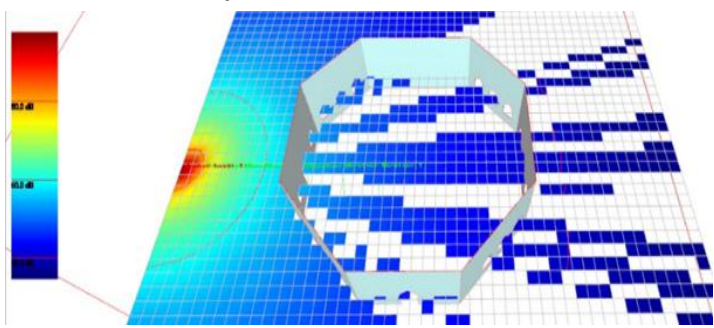

Gambar 7. Distribusi intensitas bunyi pada Gereja GMIM Kampus
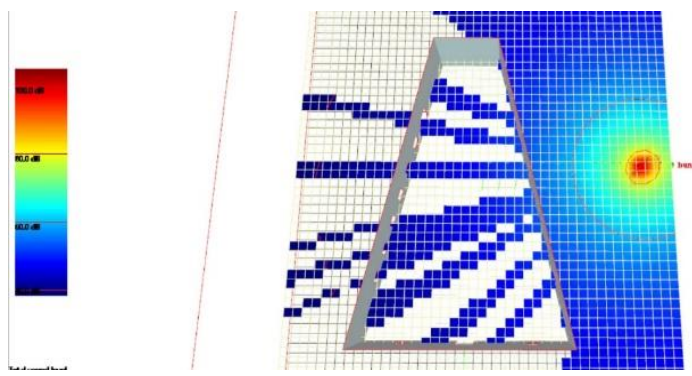

Gambar 8. Distribusi intensitas bunyi pada Gereja GMIM Bethesda 
Tabel 3. Peluang $N R$

\begin{tabular}{l|c|c|l}
\hline Metode & $\begin{array}{c}\text { Gereja GMIM } \\
\text { Kampus }\end{array}$ & $\begin{array}{c}\text { Gereja GMIN } \\
\text { Bethesda }\end{array}$ & Ruang \\
\hline Teori NR & $8.7 \mathrm{sd} 12.7 \mathrm{~dB}$ & $5.9 \mathrm{sd} 6.4 \mathrm{~dB}$ & $\begin{array}{l}\text { Terisi } 200 \\
\text { orang }\end{array}$ \\
\hline Simulasi I Simpa & $2 \mathrm{sd} 2.2 \mathrm{~dB}$ & $2.3 \mathrm{sd} 3.4 \mathrm{~dB}$ & Kosong \\
\hline Pengukuran & $7 \mathrm{sd} 7.5 \mathrm{~dB}$ & $9.3 \mathrm{sd} 16.2 \mathrm{~dB}$ & Kosong \\
\hline
\end{tabular}

\section{KESIMPULAN}

Dari hasil perhitungan, pengukuran dan simulasi dengan software terhadap kualitas bunyi didalam ruang Gereja GMIM Kampus UNSRAT dan GMIM Bethesda Ranotana, dapat disimpulkan bahwa tingkat bunyi di dalam ruang masih tergolong tidak memenuhi standar mutu kebisingan berdasarkan SNI. Tingkat reduksi bunyi bising karena faktor dinding dan arsitektur ruang dalam, secara teoretis hanya sedikit, atau tidak signifikan, yaitu hanya mencapai angka 2 sd $3.4 \mathrm{~dB}$, dalam keadaan ruang kosong. Namun berdasarkan pengukuran bisa mencapai 16.2 dB pada Gereja GMIM Bethesda dan $7.5 \mathrm{~dB}$ pada Gereja GMIM Kampus. Adapun pola distribusi rambatan bunyi kedalam ruangan, menunjukkan adanya pengaruh dari luasnya bukaan pintu, jendela dan lubang ventilasi.

\section{DAFTAR PUSTAKA}

Bojongo, M.B.P. 2020. Regulations of noise pollution emitted by revival churches and the well-being of neighboring populations in Cameroon. Environmental Economics,11(1):82-95.

Christian, O. \& Eberechi, A. 2019. Emergent Religious Bodies and Noise Pollution: Perspectives on Enugu Metropolis and Environs. Scholars International Journal of Law, Crime and Justice, 2(9): 271-277.

Drew, K., Macfarlane, R., Oiamo, T., Mullaly, M., Stefanova, D. \& Campbell, M. 2017. How Loud is Too Loud? Health Impacts of Environmental Noise in Toronto. Toronto Public Health, Technical Report, Toronto, Canada.

Du, L., Lau, S.K. \& Lee, S.E. 2019. Experimental study on sound transmission loss of plenum windows. The Journal of the Acoustical Society of America, 146:489-495.
Gemade, K.C. \& Inja, T. 2020. Tackling Noise Pollution in Urban Benue: The Role of the Church. Int. Journal on Biblical and Cognate Studies, 1:188-205.

Ibekwe, M. 2018. Tinnitus; an Index of Noise Pollution amongst Church Worshippers in Port Harcourt Metropolis. Global Journal of Otolaryngol, 18(4):62-66.

Locher, B,, Piquerez, A., Habermacher, M., Ragettli, M., Röösli, M., Brink, M., Cajochen, C., Vienneau, D., Foraster, M., Müller, U. \& Wunderli, J.M. 2018. Differences between Outdoor and Indoor Sound Levels for Open, Tilted, and Closed Windows. Int. Journal of. Environ. Research Public Health, 15(149): 2-16.

Mama, Y., Fostich, L. \& Icht, M. 2018. The impact of different background noises on the Production Effect. Acta Psychol (Amst), 185:235-242.

Mavrin, V., Makarova, I. \& Prikhodko, A. 2018. Assessment of the influence of the noise level of road transport on the state of the environment. Transportation Research Procedia, 36: 514-519.

Mediastika, C.E., Kristianro, L., Anggono, J., Suhedi, F. \& Purwaningsih, H. 2018. Open windows for natural airflow and environmental noise reduction. Architectural Science Review,61(5): 338-348.

Patel, R. 2020. Architectural Acoustic, A guide to integrated thinking. RIBA Publishing, London.

Poetiray, M.S.G., Ekasiwi, S.N.N. \& Arifianto, D. 2015. Pengukuran Kebisingan Bangunan Gereja Terbuka. Studi Kasus Gereja Puh Sarang Kediri. Proceedings of The $2^{\text {nd }} E C O$ Architecture Conference (EAC 2):265274.

Septiana, N.R. \& Widowati, E. 2017. Gangguan Pendengaran Akibat Bising. HIGEIA: J. of Public Health Researcrh and Development,1(1):73-82.

Subagio, I. 2017. Attenuasi Bising Lingkungan dan Bukaan pada Ruang Kelas Sekolah Dasar Berventilasi Alami di Tepi Jalan Raya. Media Matrasain, 14(2):1-13. 
Supriatna, U., Poniman, D. \& Kosasih. 2020. Pengaruh Jenis Klakson pada Mobil Terhadap Tingkat Kekuatan Bunyi. Jurnal Mesa Jendela Informnasi Teknik, 4(1):1-6. 